\title{
Weakening macroalgal feedbacks through shading on degraded coral reefs
}

\author{
Jan-Claas Dajka ${ }^{1,2}$ @ | Victoria Beasley ${ }^{3}$ | Gilberte Gendron ${ }^{4}$ | Jos Barlow ${ }^{1}$ | \\ Nicholas A.J. Graham ${ }^{1}$
}

${ }^{1}$ Lancaster Environment Centre, Lancaster University, Lancaster, UK

${ }^{2}$ Helmholtz Institute for Functional Marine Biodiversity, University of Oldenburg, Oldenburg, Germany

${ }^{3} \mathrm{GVI}$ Seychelles, Global Vision International, Curieuse Island, Seychelles

${ }^{4}$ Marine Parks Division, Seychelles National Parks Authority, Victoria, Seychelles

\section{Correspondence}

Jan-Claas Dajka, Lancaster Environment Centre, Lancaster University, Lancaster, UK. Email: jan-claas.dajka@hifmb.de

\section{Funding information}

Lancaster University Faculty of Science and Technology; Royal Society; Stockholm Resilience Centre

\begin{abstract}
1. Extensive and dense macroalgal fields can compromise the ecosystem function of habitat mosaics on reefs owing to their limiting effect on patch connectivity. Macroalgae can maintain and increase their dominance with effective selfreinforcing feedback mechanisms. For example, macroalgae can form dense beds, supressing coral settlement and grazing by herbivores. This compromised ecosystem function can lead to major socioeconomic and ecological changes.

2. Dense macroalgal beds were shaded with submerged shade sails of two sizes and changes to the underlying benthos and feeding rates of herbivorous fishes were recorded. The shade sails reduced the algae's ability to photosynthesize by $29 \%$. After 6 weeks, macroalgal cover was reduced by $24 \%$ under small sails and by $51 \%$ under large sails. Small shade sails reduced turf algal growth by $23 \%$, while large sails reduced growth by $82 \%$.

3. Three months after removal of the shade sails, algal beds had almost completely regrown. During this regrowth period, herbivore bites taken from the experiment's substrates were recorded, with grazing impact reducing significantly with time.

4. This study is the first to achieve macroalgal reduction via the alteration of the light regime. While macroalgae regrew in this relatively short-term experiment, shading may be a viable reef management approach that aims to maximize habitat mosaics on coral reefs, particularly if used in combination with other intervention methods.
\end{abstract}

\section{KEYWORDS}

algae, biomanipulation, fish, habitat management, new techniques, reef

\section{1 | INTRODUCTION}

Tropical coral reefs are changing globally, with corals reducing in cover and being replaced by other organisms such as algae (Hughes, 1994; Cheal et al., 2010; Graham et al., 2015). Coral-algal regime shifts can substantially alter the ecological, social and economic value of reefs (Moberg \& Folke, 1999; Hughes et al., 2010; Robinson et al., 2019), especially when systems become dominated by a few weedy algal species of low complexity (Littler \& Littler, 1988; Hughes, 1994; Mumby, 2009). With an 
increasing frequency of disturbances threatening corals (Hughes et al., 2018), future predictions of coral-dominated systems, and the ecosystem services they support, are uncertain (Williams \& Graham, 2019; Woodhead et al., 2019). The changing compositions of reefs (Graham et al., 2014) may also give way to a mosaic of habitat patches, where multiple patch reef types form an interconnected tropical seascape (Nagelkerken et al., 2015; Harborne et al., 2016; Fulton et al., 2019). The mosaic can consist of habitat types such as corals, seagrass and macroalgae that each can benefit different communities or life stages of individual species within those communities (e.g. fish) (Berkström et al., 2013; van Lier et al., 2018). Connectivity between habitat types is critical for functioning reef mosaics (Olds et al., 2018). Substantial reductions in fish diversity have been observed when the distance between coral patches was greater than $500 \mathrm{~m}$ for resident fish species (van Lier et al., 2018) or $750 \mathrm{~m}$ when considering transient foragers (Berkström et al., 2013). Further, reef mosaic integrity and overall reef ecosystem function can decrease as individual, homogeneous habitats extend and increase the space between patch habitats (Olds et al., 2018). In summary, if homogenous macroalgal patches expand and the distance between other habitat type patches, such as coral, becomes larger than their resident species' home ranges, overall species diversity can decline. Therefore, patch connectivity should be considered in management in order to maximize the functioning of each patch (Fulton et al., 2019).

Conceptual models suggest that macroalgae can be very efficient at reinforcing their spatial dominance with feedback mechanisms (Mumby \& Steneck, 2008; Nyström et al., 2012; van de Leemput et al., 2016). Feedbacks are cause-effect loops where one aspect (A) affects another (B) which in turn feeds favouring conditions back to the original aspect (A). Observational and experimental studies have identified various macroalgal reinforcing feedbacks (Hoey \& Bellwood, 2011; Dell, Longo \& Hay, 2016; Johns et al., 2018; Loffler et al., 2018; Loffler \& Hoey, 2018). For example, once stands of the common tropical macroalgal genus Sargassum reach a certain density (A), they suppress grazing by fish herbivores (B), and the reduction of feeding pressure then allows macroalgal fields to grow further (A) (Hoey \& Bellwood, 2011). In addition, limited space in these fields prevents benthic settlement by other organisms such as corals (Dell, Longo \& Hay, 2016), and can lead to the development of microbe aggregations that cause diseases in remaining corals (Smith et al., 2006). The result can be an ever-expanding homogeneous field of weedy macroalgae (Mumby, 2009) which can compromise reef mosaic connectivity (Berkström et al., 2013; van Lier et al., 2018).

In order to limit the extent of dense homogeneous macroalgal fields and maximize the ecosystem function of mosaic-style habitats (Fulton et al., 2019), studies have investigated ways to reduce algal cover. Experiments that remove macroalgae manually have had shortlived success owing to rapid regrowth probably from leftover algal attachment structures (holdfasts) (Tanner, 1995; McClanahan et al., 2001; Roff et al., 2015; Loffler et al., 2018; Loffler \& Hoey, 2018). Following an unusually long period of overcast weather
(42 days) in Kāne'ohe Bay, Hawaii, a mass-macroalgal die-off occurred, probably caused by the lack of sufficient photosynthetically active radiation (PAR) (Stimson \& Conklin, 2008). The macroalgae did not return for the 2 years of subsequent monitoring, suggesting that shading may be a feasible approach to weaken macroalgal feedbacks. Turf algae can present an additional problem because of their ability to rapidly colonize open settlement space under favourable environmental conditions (e.g. sufficient nutrient and light levels; Littler \& Littler, 1992). Turf algae can also prevent the settlement of other benthic organisms such as corals (Birrell, McCook \& Willis, 2005), colonizing open space rapidly and potentially impairing connectivity in relatively short time frames.

In this study an artificial shading experiment was established in a bay of Curieuse Island, Seychelles that was entirely dominated by dense macroalgal fields. The overarching objective was to create macroalgal-free patches and attract herbivorous fish to these patches. Specifically, the following questions were formulated: (i) does a shading period of 42 days ( 6 weeks) result in a reduction of macroalgal cover and does the shade prevent turf algae from colonizing the newly cleared space; and (ii) do herbivorous fish graze more in patches of reduced macroalgal cover?

\section{2 | METHODS}

\section{1 | Study site and organisms}

This study was conducted from January until June 2018 at Anse Papaie $\left(4.28^{\circ} \mathrm{S}, 55.73^{\circ} \mathrm{E}\right)$, Curieuse Island, Seychelles. The bay was chosen owing to its continuous, thick macroalgal beds extending to relatively deep water ( $6 \mathrm{~m}$ at high tide) and its status as a marine park to minimize boat traffic. The dominance by macroalgae probably developed following the 1998 bleaching event, which led to many Seychelles reefs shifting dominance from corals to macroalgae (Graham et al., 2015). Prevailing winds in the inner Seychelles come from the north west between December and March and start turning into south-easterly winds in late March, staying from this direction until October, followed by intense rainfall and winds through November and December ( $M$ Belmont and $\mathrm{V}$ Amelie, Seychelles Meteorological Services). With Anse Papaie on the eastern side of Curieuse, the bay remains relatively wind-sheltered from late January until mid-March. The macroalgae overstorey in the bay is primarily Sargassum spp. with some Turbinaria spp. present, while the understorey is primarily Lobophora spp. and Dictyota spp. Sargassum spp. often display strong seasonality in growth patterns worldwide. Sargassum seasonality in the inner Seychelles appears to be tied to the prevailing seasonal winds and currents (Bijoux, 2013), with senescence during the cloudy south-east wind period (from May to October) and regrowth during the predominantly clear-sky north-west wind period (December to March). This drove the choice of experimental timing of January to June, during which time skies are predominantly clear and Sargassum is not subjected to senescence, but instead is in a regrowth phase. 


\subsection{Experimental setup}

Submerged square-shaped shade sails (>98\% UV-blockage certified according to Kookaburra Shade Sails, Sydney, Australia) of two sizes ( 4 and $9 \mathrm{~m}^{2}$, five of each size) were built over continuous macroalgal fields (Figure S1). Each shade sail was mounted on four threaded steel rods (diameter $22 \mathrm{~mm}$, length $1.5 \mathrm{~m}$ ), with the rods hammered $50 \mathrm{~cm}$ into the sediment to allow at least $1 \mathrm{~m}$ between the rod's end and the water's surface at low tide (to allow boat passage) and for the algae ( $\sim 30 \mathrm{~cm}$ maximum height) not to touch the shade sails. Each sail was left with enough rope tension to allow it to oscillate $\sim 20 \mathrm{~cm}$ above and below the highest point of the rods to absorb some of the wave action and reduce the chance of ripping. The shade sail structures were put in place on 28 January 2018 and they remained fixed for 42 days until deconstruction on 11 March 2018 to prevent shifting winds from disrupting the experiment. Control plots were constructed solely of steel rods (no shade sails) on the same reef. The total experimental setup included 16 plots (five $4 \mathrm{~m}^{2}$ treatments, five $9 \mathrm{~m}^{2}$ treatments, three $4 \mathrm{~m}^{2}$ controls, three $9 \mathrm{~m}^{2}$ controls) running in rows parallel to the shoreline, at a similar depth. Plots were separated to ensure there was no overlap in shade and control plots were $15 \mathrm{~m}$ from experimental plots. Altogether, the experiment covered roughly $450 \mathrm{~m}^{2}$

\section{3 | Sampling and statistical analysis}

All sampling was conducted using snorkel gear. $\mathrm{HOBO}$ pendant loggers were deployed to measure light intensity (in lux) underneath the sails (Figure S2). The loggers were placed on PVC pipes $(35 \mathrm{~cm}$ ), keeping them above the macroalgal canopy and in the centre of each plot. Loggers were deployed in the first week of shading from 11:00 to 16:00 $\mathrm{h}$ and took light intensity readings every $10 \mathrm{~min}$. This method was replicated in control plots.

\subsection{1 | Macroalgal cover}

Planar view photographs of treatment and control plots were taken immediately before installing and immediately after taking down the sails. The process was repeated monthly following sail removal, with the last picture taken on the 11 June 2018, 3 months following shading. These pictures were compared using 'Coral Point Count with Excel extensions (CPCe)' (Kohler \& Gill, 2006) to obtain the change in percentage macroalgal cover over time.

To statistically investigate the effects of sail size and time (fixed effects), generalized linear mixed models (GLMM) were fitted to the macroalgae cover using the Ime4-package in R (Bates et al., 2015). The model was fitted with 'plot' nested in 'treatment' as a random effect to address dependencies induced by repeated measures through time. To avoid having a percentage-based response variable, macroalgae cover was used as a binary response variable ( 1 = macroalgae, 0 = no macroalgae) with each randomly allocated point in the HD photographs being one observation ( $n=50$ per photo, $n=4,000$ in total) and fitted with GLMM with a binomial distribution.

\subsection{2 | Settlement blocks: turf algal growth potential}

To simulate benthic regrowth, one settlement block $(10 \times 10 \mathrm{~cm}$, made from marine cement, mounted on an individual steel rod to raise the block above the macroalgal canopy) was deployed in the centre of each treatment and control plot when the experiment started. The cement blocks remained under the sails for the entire time of active shading. The blocks were collected with the shade sail removal and analysed for algae cover using photographs and CPCe (Kohler \& Gill, 2006). A GLMM was fitted with sail size and time as fixed effects and plot nested in treatment as a random effect. The same binary allocation as for macroalgal cover data ( $1=$ turf algae, $0=$ no turf algae) was done for the settlement blocks data $(n=30$ per photo, $n=270$ in total) and a binomial GLMM was fitted to the data.

\subsection{3 | Photosynthetic efficiency}

Every week during active shading and one additional week after, three random basal blades from different plants in each plot were collected from 09:00 to 10:00 a.m., at medium to high tide ( $40 \mathrm{~cm}$ difference). These blades were placed in a black, optically opaque bag and, within a maximum of $30 \mathrm{~min}$, taken from the field site to a wet laboratory, where the same light conditions were kept for the duration of the experiment. Each blade was analysed individually with a Junior pulseamplitude modulation chlorophyll fluorometer (Walz, ErlangenEltersdorf, Germany) using light curves that applied photo fluence rates of 120,192, 273, 414, 574, 903, 1,341 and 2,010 $\mu \mathrm{mol}$ PAR $\mathrm{m}^{-2} \mathrm{~s}^{-1}$ consecutively, with 1 min intervals in between. The interval time was sufficient to allow a return to a steady state following saturation pulses. The values obtained from measuring the three blades were averaged per plot. The light curves were used to obtain the effective photochemical quantum yield $\left(Y(I I)_{\max }=\Delta F / F m^{\prime}\right)$ as a representative measurement of photosynthetic efficiency per plot per week. A linear mixed model (LMM) was fitted to photosynthetic efficiency data with sail size and time as fixed effects and plot as a random effect. The photosynthetic efficiency [Y(II)] data met the assumptions of the LMM as an untransformed response variable with $Y(I I)$ recordings averaged for each plot $(n=112)$.

\subsection{4 | Herbivore feeding following experimental deconstruction}

After removal of the shade sails, the plots were monitored in March, April and May 2018 with six digital video cameras (GoPro Hero 4). The corner rods were left in place to outline the 4 or $9 \mathrm{~m}^{2}$ plots. To quantify the herbivore feeding impact per square metre on the 
experimental plots, the cameras were deployed on PVC arms which were mounted on one of the corner steel rods (Figure S1) of each plot, and filmed for $4 \mathrm{~h}$ between 10:00 and 14:00. A $1 \mathrm{~h}$ film segment situated at least $30 \mathrm{~min}$ after deployment and at least $30 \mathrm{~min}$ before the end of filming was analysed. Each bite taken by an individual fish and respective species was recorded. An LMM of herbivore bite data with sail size and time as fixed effects and plot nested in treatment as a random effect was fitted. The response variable of herbivore bites per square metre was $\log _{10}$-transformed with every fish being an individual observation ( $n=3,859$ ).

Models were not or were only weakly biased by collinearity (Zuur, leno \& Elphick, 2010). The residual plots of all four models suggested good model fits. Pair-wise comparison Tukey post-hoc tests were conducted for the four models using the emmeans-package in $\mathrm{R}$ (Lenth et al., 2019). All analyses were conducted in $\mathrm{R}$ version 3.5.3 (R-Core-Team, 2019). R-scripts and data are provided at an open source repository (https://github.com/JanDajka/SeyShading-2018).

\section{3 | RESULTS}

\section{1 | Macroalgal cover}

Macroalgal cover significantly declined from before shading (January) to after shading (March) on small plots of $4 \mathrm{~m}^{2}$ (Figure 1, 23.6\% reduction January vs. March shaded $4 \mathrm{~m}^{2}$ : Tukey pair-wise comparison $\left.z-\Delta_{4}=4.72, P=0.003\right)$ and large plots of $9 \mathrm{~m}^{2}(51.2 \%$ reduction January vs. March shaded $\left.9 \mathrm{~m}^{2}: \mathrm{z}-\Delta_{9}=10.25, P<0.001\right)$, while the controls showed non-significant increases in macroalgal cover $(3.33 \%$ increase January vs. March controls $4 \mathrm{~m}^{2}: \mathrm{z}-\Delta_{4}=-0.52, P=1 ; 2.67 \%$ increase January vs. March controls $9 \mathrm{~m}^{2}: \mathrm{z}-\Delta_{9}=-0.41, P=1$ ). Macroalgal cover returned following shade removal but with significant differences still present after 2 months (12\% reduction January vs. May shaded $4 \mathrm{~m}^{2}: z-\Delta_{4}=4.24, P=0.012 ; 20.4 \%$ reduction January vs. May shaded $9 \mathrm{~m}^{2}: z-\Delta_{9}=4.08, P=0.02$ ). Three months after shade removal, both plot sizes had returned to similar macroalgal cover compared with before shading (1.2\% reduction January vs. June shaded $4 \mathrm{~m}^{2}: z-\Delta_{4}=0.24, P=1 ; 7.6 \%$ reduction January vs. June shaded 9 $\left.\mathrm{m}^{2}: z-\Delta_{9}=1.52, P=0.99\right)$. Controls showed little change throughout the experiment.

\subsection{Settlement blocks: turf algal growth potential}

Turf algae covered most of the area on the previously clear settlement blocks in control plots (Figure 2). In the small shade sail plots, turf algae covered on average $67.8 \%$ (23. 37\% reduction control vs. shaded 4- $\mathrm{m}^{2}$ tiles: $z-\Delta_{4}=2.7, P=0.02$ ), while in the larger shade plots turf only covered $8.89 \%$ ( $81.9 \%$ reduction control vs. shaded 9- $\mathrm{m}^{2}$ tiles: $\left.z-\Delta_{9}=7.1, P<0.001\right)$. The rest of the cement block surface remained bare, apart from negligible bryozoan cover.

\subsection{Photosynthetic efficiency}

The photochemical quantum yield of photosystem II [Y(II)] of macroalgae in shaded conditions changed over the duration of the experiment, with noticeable decreases occurring in week 5 (Figure 3). The diversion from baseline measurements taken before the experiment (week 1) was not significant throughout the experiment for

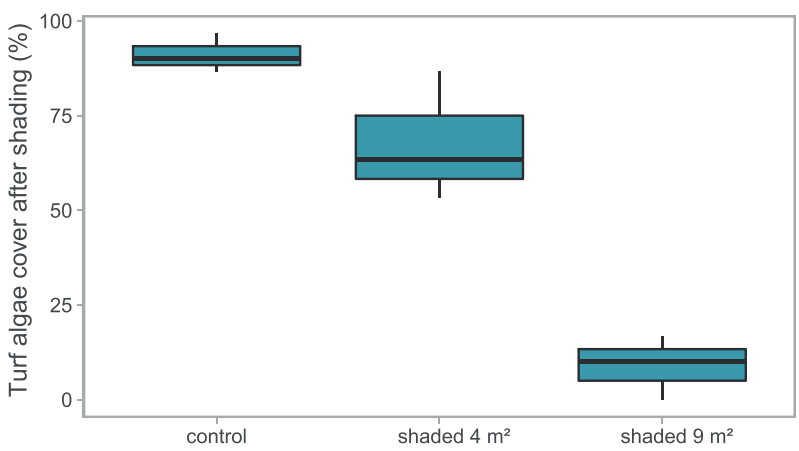

FIGURE 2 Turf algae cover (in per cent) observed on settlement blocks that were deployed in shaded plots of different sizes (4 and $9 \mathrm{~m}^{2}$ ) and unshaded control plots and collected following deconstruction of the experiment in March 2019. Central line, mean; boxplot boundaries, interquartile range; whiskers, \pm standard error
FIGURE 1 Macroalgal cover (in per cent) changes observed monthly in shaded plots and unshaded control plots of different sizes ( 4 and $9 \mathrm{~m}^{2}$ ) over the active shading period (grey area) and post-removal/algal regrowth period (white area). Central line, mean; boxplot boundaries, interquartile range; outside dot, value is $>1.5$ times and $<3$ times the interquartile range beyond either end of the box; whiskers, \pm standard error

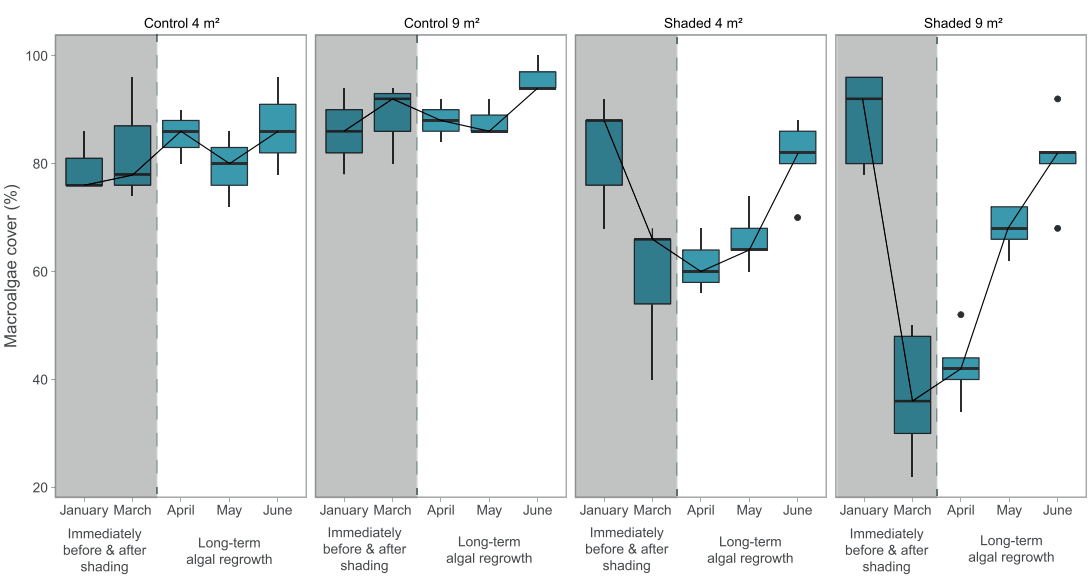



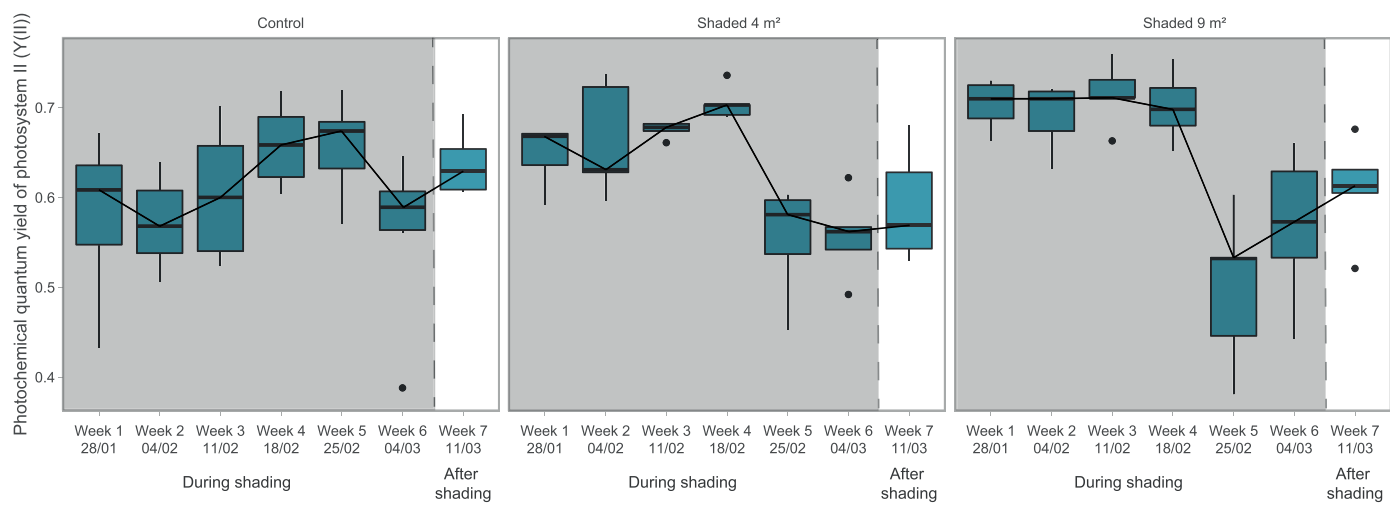

FIGURE 3 Photochemical quantum yield of photosystem II [Y(II)] of experimental Sargassum macroalgae throughout weeks of active shading (grey area) and 1 week after (white area) in shaded plots of different sizes ( 4 and $9 \mathrm{~m}^{2}$ ) and unshaded control plots. Central line, mean; boxplot boundaries, interquartile range; outside dot, value is $>1.5$ times and $<3$ times the interquartile range beyond either end of the box; whiskers, \pm standard error

shaded macroalgae in small plots (12\% reduction week 1 vs. week 5 $t-\Delta_{4}=2.6, P=0.51$ ). For large plots on the other hand, the depression in photosynthetic efficiency for shaded macroalgae in week 5 was significant (29\% reduction week 1 vs. week $\left.5: t-\Delta_{9}=5.8, P<0.001\right)$ and remained significant until week 6 (18\% reduction week 1 vs. week 6: $t-\Delta_{9}=0.1, P=0.04$ ). One week after removal of the shade sails (week 7), photosynthetic efficiency was not significantly different from values in week 1 for both plot sizes (small: 6\% reduction week 1 vs. week 7: $t-\Delta_{4}=1.6, P=0.987$; large: $9 \%$ reduction week 1 vs. week 7: $\left.t-\Delta_{9}=2.65, P=0.5\right)$. The $Y(I I)$ of macroalgae in control plots did not change significantly throughout the experiment.

\section{4 | Herbivore feeding following shade sail removal}

Regardless of plot size or herbivore functional group, bites taken from plots reduced with time following experiment deconstruction (Figure 4). Browser and grazer feeding did not differ significantly between control plots and plots that were previously shaded for small (control vs. shaded $4 \mathrm{~m}^{2}: z-\Delta_{4}=-1.415, P=0.96$ ) or large plot sizes (control vs. shaded $9 \mathrm{~m}^{2}: z-\Delta_{9}=-0.732, P=0.99$ ). However, there were significant differences between control and previously shaded plots in scraper feeding on large plots 1 month after shade-sail removal (control vs. shaded $9 \mathrm{~m}^{2}$ for scrapers in April: $\mathrm{z}-\Delta_{9}=-4.78$, $P=0.001$ ) which had subsided 2 months after removal (control vs. shaded $9 \mathrm{~m}^{2}$ for scrapers in May: $z-\Delta_{9}=-1.602, P=0.99$ ).

\section{DISCUSSION}

This study demonstrates that macroalgal reduction can be accomplished using submerged shade sails within 42 days or less, and that reduction scales with shade sail size. Shading also limits turf algal regrowth, potentially making space available to other benthic settlers. Once the shade sails were removed, a significant increase in herbivore grazing was not detected in the experimental plots, which indicates that the macroalgae-reinforcing feedback was not sufficiently weakened. The algal reduction method presented here may be used in a reef management approach that pursues the maximization of ecosystem services drawn from a habitat mosaic reefscape.

The prolonged shading probably hindered the algae's metabolic ability to a point where net-positive photosynthesis could not be sustained (Littler \& Littler, 1992; Shiu \& Lee, 2005; Teichberg, Fricke $\&$ Bischof, 2013). Initially, Sargassum was able to acclimatize to the light regime changes and did not show a loss of photosynthetic efficiency for 4 weeks, although a darkening in blade coloration was visible from week 2 (pers. obs.). The initial acclimatization to a darker light regime could be possible because the plant increases its lightharvesting pigment content to maximize photosynthesis when PAR is limiting (Littler, Littler \& Lapointe, 1988; Littler \& Littler, 1992; Abal et al., 1994; Lirman \& Biber, 2005). This photoadaptation in macroalgae is probably achieved by diverting energy away from growth and towards maximizing photosynthesis, as reported for other tropical marine macroalgae (e.g. Halimeda; Littler, Littler \& Lapointe, 1988; Teichberg, Fricke \& Bischof, 2013). At week 5, the PAR that Sargassum plants were able to harvest in shaded conditions proved insufficient to sustain photosynthesis levels required to prevent biomass loss. It is possible that reactive metabolic by-products, such as oxygen radicals, caused oxidative damage to the plant's photosystems (Shiu \& Lee, 2005). In addition, the constant variations in light intensity reaching the algae induced by movement of the shade sails in wave action may have proven challenging to photoadaptation and the maintenance of net-positive photosynthesis (Taylor \& Long, 2017). In some cases, intermittent light regimes in seaweed canopies have been shown to stimulate growth and result in higher productivity within canopy environments (Bennett et al., 2015); however, the evidence presented here suggests the opposite.

The decrease in photosynthetic efficiency probably resulted in the observed discoloration of the plants and eventually led to a disintegration of the algal thalli. This may have affected the palatability of the plants to herbivores. The palatability of macroalgae to herbivores 


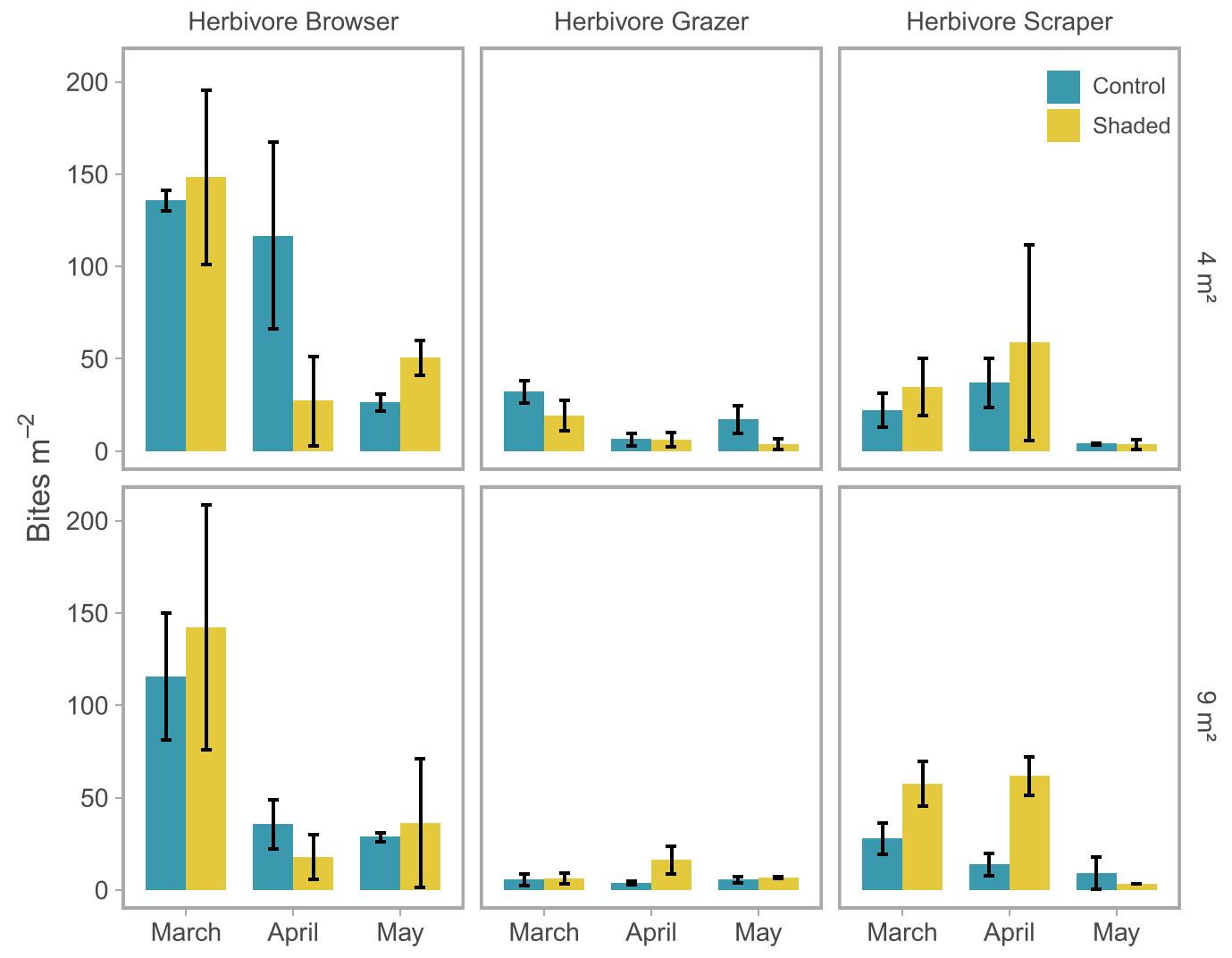

FIGURE 4 Bites per square metre taken by three herbivore fish functional groups (browsers, grazers, scrapers) from shaded and control plots of different sizes $\left(4\right.$ and $9 \mathrm{~m}^{2}$ ) in $1 \mathrm{~h}$ video samples. Recordings were taken monthly following shade sail deconstruction; error bars, \pm standard error

seems to partly depend on the carbon-to-nitrogen ratios ( $\mathrm{C}: \mathrm{N}$ ratio) within the plant tissue (Vergés et al., 2011). Lower C:N ratios have been experimentally associated with increased herbivore palatability (Barile, Lapointe \& Capo, 2004; Van Alstyne, Pelletreau \& Kirby, 2009). Given that changing light-regimes affect plants' photosynthesis and therefore their ability to maintain a C:N ratio (Teichberg, Fricke \& Bischof, 2013), this ratio can be expected to have changed in this experiment. Unfortunately, palatability using C: $\mathrm{N}$ ratios could not be quantified in this experiment owing to the lack of necessary equipment on Curieuse (e.g. a $-80^{\circ} \mathrm{C}$ freezer).

In addition to the decrease in photosynthetic efficiency, herbivorous fish, which are abundant in the area (Robinson et al., 2019), could have grazed on the experimental algae and thus contributed to the reduction in macroalgal cover observed. While grazing footage of herbivorous fish was obtained after the removal of the shade sails, this could not be done while the shade sails were in place. A camera angle that could balance a view far above the macroalgal canopy $(\sim 30 \mathrm{~cm}$ maximum height) to see the substrate clearly enough to identify the fish grazing and still be below the lowest point of the shade sail (the sail was $\sim 60 \mathrm{~cm}$ above the substrate) could not be set up. In order to obtain grazing footage while the shade sails were in place, the shading structures would have needed to be built higher above the substrate, which then would have reduced the shading efficiency and the ability of boats to pass overhead. In addition, the HD photographs enabled macroalgae to be identified to genus level, which was more than $90 \%$
Sargassum cover in our experiment. Therefore, the majority of the results relate to Sargassum. However, since the photographs were taken from a planar view, this only represents the overstorey and inferences cannot be made about the understorey that might have been growing under the Sargassum canopy. Lobophora algae, for instance, can grow in the understorey of other algae (Roff et al., 2015) and this could have affected the preferred food source of some herbivores.

The macroalgae-reinforcing feedback was not weakened sufficiently, as the experimental plots with reduced macroalgal cover after shading did not show significantly higher feeding rates by herbivorous fish compared with the controls. The macroalgae regrew to roughly pre-experimental cover levels within 3 months. After deconstruction on the 11 March 2018, herbivorous fishes remained in the plot areas for the first post-experimental month and grazed more intensely on both the shaded and control plots in March, before declining gradually. There are some plausible mechanisms for this. Firstly, the experimental design may simply have lacked statistical power, resulting in the large variability in the dataset. As mentioned, browsing herbivores may have been involved in the macroalgal reduction while the shading structures were in place. Their involvement after shade sail removal may not have been detectable by the experimental setup because, with returning light, the macroalgae may have been able to reestablish their unpalatability through secondary metabolites. Scraping parrotfish on the other hand seemed to preferentially target large 
shaded plots in the March surveys. Since scraping parrotfish target turf algae and microbial communities in dead reef structures (Bellwood \& Choat, 1990; Streelman et al., 2002; Bonaldo, Hoey \& Bellwood, 2014; Clements et al., 2017), and the experiment cleared most macroalgae and exposed more open settlement space that could readily be colonized after sail removal, resources for scrapers would be abundant in the experimental plots. Another explanation could be that herbivores may have become used to feeding around the structures, such that the intense grazing in March was a lag effect of the structural attraction, as reef fish can be attracted by structures similar to ours (Kerry \& Bellwood, 2015). As distance between control and experimental plots is probably incorporated within fish foraging ranges, declines in feeding rates occurring gradually for both plot types may be expected. Future studies could employ alternative control structures to help reduce the uncertainty in the above-described issue. This could include controls without any structure, not even rods, in addition to controls with non-shading, transparent sails to account for the movement of the sail and for potential fish scaring.

The observed regrowth rate of 3 months roughly matches that of a previous study that also used percentage cover as a metric: Sargassum, 2 months (McClanahan et al., 2001); S. herporhizum, $<1$ month; S. sinicola, >3 months (McCourt, 1985). However, macroalgal biomass, and associated feedback mechanisms, may take longer to re-establish (Loffler \& Hoey, 2018). The 6-week shading method led to a significant reduction of macroalgal cover and we can suggest a combination of possible reduction mechanisms. An interesting question remains as to whether the algae regrew because of low herbivory, or the herbivores moved because the macroalgal feedbacks were not sufficiently weakened. Along with our previous reasoning, we believe the latter. It could be that with the removal of the shade sails, the return to a normal light regime allowed the macroalgae to again reinforce their unpalatability to herbivores which then led to herbivore disengagement and regaining of strength in the self-reinforcing feedback.

While other studies have reduced macroalgal cover by manual removal (McClanahan et al., 2001; Loffler et al., 2018; Loffler \& Hoey, 2018), the present study is the first to do so via shading for a limited time frame. The time to physically keep the shade sails in place was restricted by the increase in wave action. While this study confirmed that localized macroalgal reduction can be achieved within 42 days as indicated by an observational study (Stimson \& Conklin, 2008), the clearing of the plot of holdfasts could not be achieved. Given the resistant nature of the algae's holdfasts (Ceccarelli et al., 2018), we think that it would be interesting to see whether a longer shading time would result in a reduction of holdfasts, since most of the observed macroalgal regrowth following shade sail removal probably came from leftover holdfasts (Loffler et al., 2018). Alternatively, since the shorter 6 week time frame might be particularly interesting to management as the longer time frame might not be a realistic management tool (Ceccarelli et al., 2018), perhaps a combination with other intervention methods, e.g. shading areas manually cleared of holdfasts, could be of greater management use. Based on the photographs before and after shading, we believe that holdfast densities decreased.

Notably, the efficiency of macroalgal reduction did scale with shade sail size. Future studies could consider using significantly larger sails to maximize macroalgal reduction and perhaps enable them to record a clearing of holdfasts as well. Scientifically, it would be interesting to see whether the increasing trend of macroalgal reduction with sail size continues. From a management perspective, we do not believe that shade sails much larger than $9 \mathrm{~m}^{2}$ would be practical. The $9 \mathrm{~m}^{2}$ shade sails did present a slight loss in tension towards the end of the experiment. This could result in the centre of the shade sail dragging on the substrate and abrading macroalgae and other benthic organisms. While the loss in tension in this experiment was not drastic enough for sails to make contact with the substrate or the algae, shade sails larger than $9 \mathrm{~m}^{2}$ may well present this problem. In addition, coral reef managers may find the short 6 week time frame and relatively small $9 \mathrm{~m}^{2}$ shade sail size particularly appealing. As suggested throughout this manuscript, this method does hold most potential for management pursuing a mosaic reefscape approach.

That other benthic settlers (e.g. corals) can grow on the cleared settlement space could not be demonstrated because of the limited experimental period. Based on coral settlement studies that monitored coral settlement for 5-29 months (Babcock \& Mundy, 1996; Mangubhai, Harrison \& Obura, 2007; Yadav et al., 2016), we suggest that future studies find sites and/or shading structures that allow for a longer period of uninterrupted shading to be able to observe a potential increase in coral recruits.

This study tested a novel method of macroalgal reduction that could be used and further developed for localized intervention approaches that aim to manage productive reefs made up of a mosaic of interconnected habitat patches. We recognize the importance of natural macroalgal reefs (Fulton et al., 2019) and that macroalgae will increasingly be a part of ecological (Nagelkerken et al., 2015; Harborne et al., 2016) and socioeconomic reef potential (Robinson et al., 2019). However, since self-reinforcing feedbacks can lead macroalgae to dominate continuous stretches of reef and thereby expand beyond connectivity thresholds that are critical for a productive mosaic, reef management needs ways to address macroalgal expansion. While the method presented here did not interrupt macroalgae-reinforcing feedbacks to the point where feeding rates by herbivorous fish significantly increased, it weakened them so that macroalgal cover could be significantly reduced. The presented method reduced macroalgal cover by altering the light regime and may be useful as part of a suite of intervention strategies, particularly to shade areas cleared of holdfasts, and perhaps aiding coral recruitment on newly provided settlement substrates.

\section{ACKNOWLEDGEMENTS}

We thank Seychelles National Parks Authority for logistical support, Anto Suzette, Andrew Jacques, Jerrick Jean-Baptiste, Derreck Louange, Morgan Purdy, Jimmy Lesperance, Allen Cedras, Michel Monthy and Nathachia Pierre for their in-field assistance, and Samuel 
Taylor for his help interpreting plant photosynthetic efficiency data. This work was supported through grants from the Royal Society, Stockholm Resilience Centre and a Lancaster University Faculty of Science and Technology PhD studentship.

\section{DECLEARATION OF INTERESTS}

The authors declare that they have no known competing financial interests or personal relationships that could have appeared to influence the work reported in this paper.

\section{1 | OPEN RESEARCH BADGES}

(II)

This article has earned an Open Data badge for making publicly available the digitally-shareable data necessary to reproduce the reported results. The data is available at https://github.com/JanDajka/ SeyShading-2018.

\section{ORCID}

\section{Jan-Claas Dajka (D) https://orcid.org/0000-0002-0797-9229}

\section{REFERENCES}

Abal, E.G., Loneragan, N., Bowen, P., Perry, C.J., Udy, J.W. \& Dennison, W.C. (1994). Physiological and morphological responses of the seagrass Zostera capricorni Aschers, to light intensity. Journal of Experimental Marine Biology and Ecology, 178(1), 113-129. https://doi. org/10.1016/0022-0981(94)90228-3

Babcock, R.C. \& Mundy, C.N. (1996). Coral recruitment: Consequences of settlement choice for early growth and survivorship in two scleractinians. Journal of Experimental Marine Biology and Ecology, 206 (1-2), 179-201. https://doi.org/10.1016/S0022-0981(96)02622-6

Barile, P.J., Lapointe, B.E. \& Capo, T.R. (2004). Dietary nitrogen availability in macroalgae enhances growth of the sea hare Aplysia californica (Opisthobranchia: Anaspidea). Journal of Experimental Marine Biology and Ecology, 303(1), 65-78. https://doi.org/10.1016/j.jembe.2003. 11.004

Bates, D., Maechler, M., Bolker, B. \& Walker, S. (2015). Fitting linear mixed-effects models using Ime4. Journal of Statistical Software, 67(1), 1-48. https://doi.org/10.18637/jss.v067.i01

Bellwood, D.R. \& Choat, J.H. (1990). A functional analysis of grazing in parrotfishes (family Scaridae): The ecological implications. In: M.N. Bruton (Ed.) Alternative life-history styles of fishes. Dordrecht: Springer, pp. 189-214.

Bennett, S., Wernberg, T., de Bettignies, T., Kendrick, G.A., Anderson, R.J., Bolton, J.J. et al. (2015). Canopy interactions and physical stress gradients in subtidal communities. Ecology Letters, 18(7), 677-686. https:// doi.org/10.1111/ele.12446

Berkström, C., Lindborg, R., Thyresson, M. \& Gullström, M. (2013). Assessing connectivity in a tropical embayment: Fish migrations and seascape ecology. Biological Conservation, 166(1), 43-53. https://doi. org/10.1016/j.biocon.2013.06.013

Bijoux, J.P. (2013). Reef fish spawning aggregation sites: The ecology of aggregating and resident species. PhD thesis, Université de la Méditerranée Aix-Marseille II.

Birrell, C.L., McCook, L.J. \& Willis, B.L. (2005). Effects of algal turfs and sediment on coral settlement. Marine Pollution Bulletin, 51(1-4), 408-414. https://doi.org/10.1016/j.marpolbul.2004.10.022

Bonaldo, R., Hoey, A. \& Bellwood, D. (2014). The ecosystem roles of parrotfishes on tropical reefs. In: Oceanography and marine biology -
An annual review, Vol. 52, $1^{\text {st }}$ edition. Boca Raton: Taylor \& Francis, pp. 81-132.

Ceccarelli, D.M., Loffler, Z., Bourne, D.G., Al Moajil-Cole, G.S., BoströmEinarsson, L., Evans-Illidge, E. et al. (2018). Rehabilitation of coral reefs through removal of macroalgae: State of knowledge and considerations for management and implementation. Restoration Ecology, 26(5), 827-838. https://doi.org/10.1111/rec.12852

Cheal, A.J., MacNeil, M.A., Cripps, E., Emslie, M.J., Jonker, M., Schaffelke, B. et al. (2010). Coral-macroalgal phase shifts or reef resilience: Links with diversity and functional roles of herbivorous fishes on the Great Barrier Reef. Coral Reefs, 29(4), 1005-1015. https://doi. org/10.1007/s00338-010-0661-y

Clements, K.D., German, D.P., Piché, J., Tribollet, A. \& Choat, J.H. (2017). Integrating ecological roles and trophic diversification on coral reefs: Multiple lines of evidence identify parrotfishes as microphages. Biological Journal of the Linnean Society, 120(4), 729-751. https://doi.org/10. 1111/bij.12914

Dell, C.L.A., Longo, G.O. \& Hay, M.E. (2016). Positive feedbacks enhance macroalgal resilience on degraded coral reefs. PLoS ONE, 11(5), e0155049. https://doi.org/10.1371/journal.pone.0155049

Fulton, C.J., Abesamis, R.A., Berkström, C., Depczynski, M., Graham, N.A.J., Holmes, T.H. et al. (2019). Form and function of tropical macroalgal reefs in the Anthropocene. Functional Ecology, 33(6), 989-999. https://doi.org/10.1111/1365-2435.13282

Graham, N.A., Jennings, S., MacNeil, M.A., Mouillot, D. \& Wilson, S.K. (2015). Predicting climate-driven regime shifts versus rebound potential in coral reefs. Nature, 518(7537), 94-97. https://doi.org/10.1038/ nature14140

Graham, N.A.J., Cinner, J.E., Norström, A.V. \& Nyström, M. (2014). Coral reefs as novel ecosystems: Embracing new futures. Current Opinion in Environmental Sustainability, 7(1), 9-14. https://doi.org/10.1016/j. cosust.2013.11.023

Harborne, A.R., Nagelkerken, I., Wolff, N.H., Bozec, Y.-M., Dorenbosch, M., Grol, M.G.G. et al. (2016). Direct and indirect effects of nursery habitats on coral-reef fish assemblages, grazing pressure and benthic dynamics. Oikos, 125(7), 957-967. https://doi.org/10. 1111/oik.02602

Hoey, A.S. \& Bellwood, D.R. (2011). Suppression of herbivory by macroalgal density: A critical feedback on coral reefs? Ecology Letters, 14(3), 267-273. https://doi.org/10.1111/j.1461-0248.2010. 01581.x

Hughes, T.P. (1994). Catastrophes, phase shifts and large-scale degradation of a Caribbean coral reef. Science, 265(5178), 1547-1551. https://doi.org/10.1126/science.265.5178.1547

Hughes, T.P., Anderson, K.D., Connolly, S.R., Heron, S.F., Kerry, J.T., Lough, J.M. et al. (2018). Spatial and temporal patterns of mass bleaching of corals in the Anthropocene. Science, 359(6371), 80-83. https://doi.org/10.1126/science.aan8048

Hughes, T.P., Graham, N.A.J., Jackson, J.B.C., Mumby, P.J. \& Steneck, R.S. (2010). Rising to the challenge of sustaining coral reef resilience. Trends in Ecology \& Evolution, 25(11), 633-642. https://doi.org/10. 1016/j.tree.2010.07.011

Johns, K.A., Emslie, M.J., Hoey, A.S., Osborne, K., Jonker, M.J. \& Cheal, A.J. (2018). Macroalgal feedbacks and substrate properties maintain a coral reef regime shift. Ecosphere, 9(7), 1-15. https://doi.org/10.1002/ecs2. 2349

Kerry, J.T. \& Bellwood, D.R. (2015). Competition for shelter in a highdiversity system: Structure use by large reef fishes. Coral Reefs, 35(1), 245-252. https://doi.org/10.1007/s00338-015-1362-3

Kohler, K.E. \& Gill, S.M. (2006). Coral Point Count with Excel extensions (CPCe): A Visual Basic program for the determination of coral and substrate coverage using random point count methodology. Computers \& Geosciences, 32(9), 1259-1269. https://doi.org/10.1016/j.cageo.2005. 11.009 
Lenth, R., Singmann, H., Love, J., Buerkner, P. \& Herve, M. (2019). Estimated marginal means, aka least-squares means. $\mathrm{R}$ Package Version 1.3.2.

Lirman, D. \& Biber, P. (2005). Seasonal dynamics of macroalgal communities of the Northern Florida Reef Tract. Botanica Marina, 43(4), 305-314. https://doi.org/10.1515/bot.2000.033

Littler, M.M. \& Littler, D.S. (1988). Structure and role of algae in tropical reef communities. In: C.A. Lembi, J.R. Waaland (Eds.) Algae and human affairs. Cambridge: Cambridge University Press.

Littler, M.M. \& Littler, D.S. (1992). Photosynthesis vs. irradiance curves for six species of macroalgae from the Seychelles Islands under four levels of nutrient enrichment. Atoll Research Bulletin, 374(1), 1-14. https:// doi.org/10.5479/si.00775630.374.1

Littler, M.M., Littler, D.S. \& Lapointe, B.E.J.C.R. (1988). A comparison of nutrient- and light-limited photosynthesis in psammophytic versus epilithic forms of Halimeda (Caulerpales, Halimedaceae) from the Bahamas. Coral Reefs, 6(3-4), 219-225. https://doi.org/10.1007/ bf00302018

Loffler, Z., Graba-Landry, A., Kidgell, J.T., McClure, E.C., Pratchett, M.S. \& Hoey, A.S.J.C.R. (2018). Holdfasts of Sargassum swartzii are resistant to herbivory and resilient to damage. Coral Reefs, 37(4), 1075-1084. https://doi.org/10.1007/s00338-018-01745-w

Loffler, Z. \& Hoey, A.S. (2018). Canopy-forming macroalgal beds (Sargassum) on coral reefs are resilient to physical disturbance. Journal of Ecology, 106(3), 1156-1164. https://doi.org/10.1111/1365-2745.12875

Mangubhai, S., Harrison, P.L. \& Obura, D.O. (2007). Patterns of coral larval settlement on lagoon reefs in the Mombasa Marine National Park and Reserve, Kenya. Marine Ecology Progress Series, 348(1), 149-159. https://doi.org/10.3354/meps07090

McClanahan, T.R., McField, M., Huitric, M., Bergman, K., Sala, E., Nyström, M. et al. (2001). Responses of algae, corals and fish to the reduction of macroalgae in fished and unfished patch reefs of Glovers Reef Atoll, Belize. Coral Reefs, 19(4), 367-379. https://doi.org/10. 1007/s003380000131

McCourt, R.M. (1985). Reproductive biomass allocation in three Sargassum species. Oecologia, 67(1), 113-117. https://doi.org/10.1007/ BF00378460

Moberg, F. \& Folke, C. (1999). Ecological goods and services of coral reef ecosystems. Ecological Economics, 29(2), 215-233. https://doi.org/10. 1016/S0921-8009(99)00009-9

Mumby, P. \& Steneck, R. (2008). Coral reef management and conservation in light of rapidly evolving ecological paradigms. Trends in Ecology \& Evolution, 23(10), 555-563. https://doi.org/10.1016/j.tree.2008. 06.011

Mumby, P.J. (2009). Phase shifts and the stability of macroalgal communities on Caribbean coral reefs. Coral Reefs, 28(3), 761-773. https://doi. org/10.1007/s00338-009-0506-8

Nagelkerken, I., Sheaves, M., Baker, R. \& Connolly, R.M. (2015). The seascape nursery: A novel spatial approach to identify and manage nurseries for coastal marine fauna. Fish and Fisheries, 16(2), 362-371. https://doi.org/10.1111/faf.12057

Nyström, M., Norström, A.V., Blenckner, T., de la Torre-Castro, M., Eklöf, J. S., Folke, C. et al. (2012). Confronting feedbacks of degraded marine ecosystems. Ecosystems, 15(5), 695-710. https://doi.org/10.1007/ s10021-012-9530-6

Olds, A.D., Nagelkerken, I., Huijbers, C.M., Gilby, B.L., Pittman, S.J. \& Schlacher, T.A. (2018). Connectivity in coastal seascapes. In: S.J. Pittman (Ed.) Seascape ecology. Oxford: John Wiley \& Sons, pp. 261-292.

R-Core-Team. (2019). R: A language and environment for statistical computing. Vienna: R Foundation for Statistical Computing.

Robinson, J.P.W., Wilson, S.K., Robinson, J., Gerry, C., Lucas, J., Assan, C. et al. (2019). Productive instability of coral reef fisheries after climatedriven regime shifts. Nature Ecology \& Evolution, 3(2), 183-190. https://doi.org/10.1038/s41559-018-0715-z
Roff, G., Doropoulos, C., Zupan, M., Rogers, A., Steneck, R.S., Golbuu, Y. et al. (2015). Phase shift facilitation following cyclone disturbance on coral reefs. Oecologia, 178(4), 1193-1203. https://doi.org/10.1007/ s00442-015-3282-x

Shiu, C.-T. \& Lee, T.-M. (2005). Ultraviolet-B-induced oxidative stress and responses of the ascorbate-glutathione cycle in a marine macroalga Ulva fasciata. Journal of Experimental Botany, 56(421), 2851-2865. https://doi.org/10.1093/jxb/eri277

Smith, J.E., Shaw, M., Edwards, R.A., Obura, D., Pantos, O., Sala, E. et al. (2006). Indirect effects of algae on coral: Algae-mediated, microbeinduced coral mortality. Ecology Letters, 9(7), 835-845. https://doi. org/10.1111/j.1461-0248.2006.00937.x

Stimson, J. \& Conklin, E. (2008). Potential reversal of a phase shift: The rapid decrease in the cover of the invasive green macroalga Dictyosphaeria cavernosa Forsskål on coral reefs in Kāne'ohe Bay, Oahu, Hawai 'i. Coral Reefs, 27(1), 717-726. https://doi.org/10.1007/ s00338-008-0409-0

Streelman, J.T., Alfaro, M., Westneat, M.W., Bellwood, D.R. \& Karl, S.A. (2002). Evolutionary history of the parrotfishes: Biogeography, comorphology, and comparative diversity. Evolution, 56(5), 961-971. https://doi.org/10.1111/j.0014-3820.2002.tb01408.x

Tanner, J.E. (1995). Competition between scleractinian macroalgae: An experimental corals and investigation of coral growth, survival and reproduction. Journal of Experimental Marine Biology and Ecology, 190 (2), 151-168. https://doi.org/10.1016/0022-0981(95)00027-O

Taylor, S.H. \& Long, S.P. (2017). Slow induction of photosynthesis on shade to sun transitions in wheat may cost at least $21 \%$ of productivity. Philosophical Transactions of the Royal Society, B: Biological Sciences, 372(1730), 20160543. https://doi.org/10.1098/ rstb.2016.0543

Teichberg, M., Fricke, A. \& Bischof, K. (2013). Increased physiological performance of the calcifying green macroalga Halimeda opuntia in response to experimental nutrient enrichment on a Caribbean coral reef. Aquatic Botany, 104(1), 25-33. https://doi.org/10.1016/j. aquabot.2012.09.010

Van Alstyne, K.L., Pelletreau, K.N. \& Kirby, A. (2009). Nutritional preferences override chemical defenses in determining food choice by a generalist herbivore, Littorina sitkana. Journal of Experimental Marine Biology and Ecology, 379(1-2), 85-91. https://doi.org/10.1016/j. jembe.2009.08.002

van de Leemput, I.A., Hughes, T.P., van Nes, E.H. \& Scheffer, M. (2016). Multiple feedbacks and the prevalence of alternate stable states on coral reefs. Coral Reefs, 35(3), 1-9. https://doi.org/10.1007/s00338016-1439-7

van Lier, J.R., Wilson, S.K., Depczynski, M., Wenger, L.N. \& Fulton, C.J. (2018). Habitat connectivity and complexity underpin fish community structure across a seascape of tropical macroalgae meadows. Landscape Ecology, 33(8), 1287-1300. https://doi.org/10.1007/s10980018-0682-4

Vergés, A., Vanderklift, M.A., Doropoulos, C. \& Hyndes, G.A. (2011). Spatial patterns in herbivory on a coral reef are influenced by structural complexity but not by algal traits. PLoS ONE, 6(2), e17115. https://doi. org/10.1371/journal.pone.0017115

Williams, G.J. \& Graham, N.A. (2019). Rethinking coral reef functional futures. Functional Ecology, 33(6), 942-947. https://doi.org/10.1111/ 1365-2435.13374

Woodhead, A.J., Hicks, C.C., Norström, A.V., Williams, G.J. \& Graham, N.A. J. (2019). Coral reef ecosystem services in the Anthropocene. Functional Ecology, 33(6), 1023-1034. https://doi.org/10.1111/13652435.13331

Yadav, S., Rathod, P., Alcoverro, T. \& Arthur, R.J.C.R. (2016). 'Choice' and destiny: The substrate composition and mechanical stability of settlement structures can mediate coral recruit fate in post-bleached reefs. Coral Reefs, 35(1), 211-222. https://doi.org/10.1007/s00338-0151358-z 
Zuur, A.F., leno, E.N. \& Elphick, C.S. (2010). A protocol for data exploration to avoid common statistical problems. Methods in Ecology and Evolution, 1(1), 3-14. https://doi.org/10.1111/j.2041-210X.2009.00001.x

\section{SUPPORTING INFORMATION}

Additional supporting information may be found online in the Supporting Information section at the end of this article.
How to cite this article: Dajka J-C, Beasley V, Gendron G, Barlow J, Graham NAJ. Weakening macroalgal feedbacks through shading on degraded coral reefs. Aquatic Conserv: Mar Freshw Ecosyst. 2021;31:1660-1669. https://doi.org/10. 1002/aqc.3546 